Radiation-driven hydrodynamics of high-Z hohlraums on the National Ignition Facility

E. L. Dewald, L. J. Suter, O. L. Landen, B. R. Thomas, J. P. Holder, F. D. Lee, K. M. Campbell, J. Schein, F. A. Weber, D. G. Pellinen, M. B. Schneider, J. R. Celeste, J. W. McDonald, J. M. Foster, C. Niemann, B. K. Young, A. J. Mackinnon, S. Dixit, C. A. Haynam, M. J. Shaw, R. E. Turner, R. L. Kauffman, S. H. Glenzer, L. J. Atherton, R. E. Bonanno, S. N. Dixit, D. C. Eder, G. Holtmeier, D. H. Kalantar, A. E. Koniges, B. J. MacGowan, K. R. Manes, D. H. Munro, J. R. Murray, T. G. Parham, B. M. Van Wonterghem, R. J. Wallace, P. J. Wegner, P. K. Whitman, B. A. Hammel, E. I. Moses

June 14, 2005

Physical Review Letters 
This document was prepared as an account of work sponsored by an agency of the United States Government. Neither the United States Government nor the University of California nor any of their employees, makes any warranty, express or implied, or assumes any legal liability or responsibility for the accuracy, completeness, or usefulness of any information, apparatus, product, or process disclosed, or represents that its use would not infringe privately owned rights. Reference herein to any specific commercial product, process, or service by trade name, trademark, manufacturer, or otherwise, does not necessarily constitute or imply its endorsement, recommendation, or favoring by the United States Government or the University of California. The views and opinions of authors expressed herein do not necessarily state or reflect those of the United States Government or the University of California, and shall not be used for advertising or product endorsement purposes. 


\title{
Radiation-driven hydrodynamics of high-Z hohlraums on the National Ignition Facility
}

\author{
E.L. Dewald, L.J. Suter, O.L. Landen, B.R. Thomas*, J.P. Holder, F.D. Lee, K.M. \\ Campbell, J. Schein, F.A. Weber, D.G. Pellinen\#, M.B. Schneider, J.R. Celeste, J.W. \\ McDonald, J.M. Foster*, C. Niemann, B.K. Young, A.J. Mackinnon, S. Dixit, C.A. \\ Haynam, M.J. Shaw, R.E. Turner, R.L. Kauffman, S.H. Glenzer, L.J. Atherton, R.E. \\ Bonanno, S.N. Dixit, D.C. Eder, G. Holtmeier, D.H. Kalantar, A.E. Koniges, B.J. \\ MacGowan, K.R. Manes, D.H. Munro, J.R. Murray, T.G. Parham, B.M. Van \\ Wonterghem, R.J. Wallace, P.J. Wegner, P.K. Whitman, B.A. Hammel, and E.I. Moses \\ LLNL, P.O. Box 808, Livermore, CA 94550 \\ *AWE Aldermaston, Reading, RG7 4PR, United Kingdom \\ ${ }^{\sharp}$ Bechtel-Nevada, Livermore, CA 94550
}

PACS numbers: $52.50 . J \mathrm{~m}, 52.40 . \mathrm{Nk}, 52.58 . \mathrm{Ns}, 52.70 . \mathrm{Kz}$

\begin{abstract}
:
The first hohlraum experiments on the National Ignition Facility with four laser beams tested radiation temperature limits imposed by plasma filling. For a variety of hohlraum sizes and pulse lengths, the measured x-ray flux shows signatures of filling that coincide with hard x-ray emission from plasma streaming out of the hohlraum. These observations agree with hydrodynamic simulations and with an analytical model that includes hydrodynamic and coronal radiative losses. The modeling predicts radiation temperature limits with full NIF greater and of longer duration than for ignition hohlraums.
\end{abstract}


The soft $\mathrm{x}$-ray environment created in high- $Z$ hohlraums heated by energetic laser beams is used to drive fuel capsules in indirect-drive inertial confinement fusion (ICF) experiments and to drive physics packages in high energy density (HED) studies $[1,2]$. It has been shown analytically [3] that plasma filling by hohlraum wall ablation $[4,5]$ imposes an upper bound to hohlraum x-ray production. Current simulations indicate that hohlraums used in ICF are optimized to drive a fusion capsule to ignition before reaching the x-ray production limits. On the other hand, many HED applications require a long sustained soft $x$-ray drive [6,7]. These experiments will approach the limits in $T_{R}-\tau$ space, where $T_{R}$ is the hohlraum peak radiation temperature and $\tau$ is the time at which the internal hohlraum radiation flux will begin to drop or roll-over, even before the laser pulse terminates. This occurs when the ablated hohlraum wall plasma reaches a density threshold that prevents the laser from propagating into the hohlraum due to absorption or backscattering. It was originally proposed [3] that this roll-over time $\tau$ is determined by laser-plasma instabilities when the plasma density approaches $0.1 n_{c}$, where $n_{c}\left[\mathrm{~cm}^{-3}\right]=1.1$ $10^{21} / \lambda^{2}\left[\mu \mathrm{m}^{2}\right]$ is the critical density for laser light $\lambda$. However, hohlraum experiments with short laser pulse duration have performed properly well beyond the time at which they fill to $0.1 n_{c}[8,9]$ indicating that a critical experimental test of hohlraum fill modeling is required for assessing long radiation drive options.

In this paper we present results from experiments, numerical simulations and analytic modeling, demonstrating vacuum hohlraum performance with a sustained radiation drive over time scales consistent with a higher fill density limit.

The National Ignition Facility (NIF) that is currently under construction [10] is a 192 laser beam system that is designed to deliver up to $1.8 \mathrm{MJ}$ of energy at a wavelength of $\lambda_{0}$ $=351 \mathrm{~nm}$. The laser is designed for indirect drive ICF and will also be used for a variety 
of HED experiments. Recently, the first four laser beams were activated and experiments were performed successfully to study laser beam propagation in long scale plasmas with lengths of gas-filled ignition hohlraums [11]. In this study we present the first hohlraum experiments on the NIF that employ a unique feature of the NIF laser namely the capability to provide long, steady laser drives with variable pulse lengths up to $20 \mathrm{~ns}$.

We used cylindrical Au hohlraums of various sizes with a single LEH and irradiated the hohlraum back wall with the four laser beams effectively forming an $f / 8$ cone that propagates along the hohlraum axis. Full aperture phase plates and polarization smoothing were installed on the laser beams providing a uniform intensity profile spot with a radial profile that is approximated by a $\mathrm{n}=5$ super-Gaussian with a $500 \mu \mathrm{m}$ diameter (1/e points) with best focus placed at the LEH [11]. Constant power (flattop) laser pulses with $100 \mathrm{ps}$ rise and fall times were used with energies between 5 and $17 \mathrm{~kJ}$ and pulse lengths between 2 and $9 \mathrm{~ns}$. The Au hohlraum walls were $5 \mu \mathrm{m}$ thick, backed by a $100 \mu \mathrm{m} \mathrm{CH}$ coating, allowing us to measure spatially resolved Au L-shell emission $(>9 \mathrm{keV})$ and to infer the hohlraum plasma fill dynamics [12]. We used a gated framing camera filtered with $\mathrm{Al}$ for photon energies $>6 \mathrm{keV}$, however when viewing through the $5 \mu \mathrm{m}$ thick hohlraum Au walls the total filtering transmits $>9 \mathrm{keV}$ x rays.

The hohlraum radiation temperature was measured with temporal and spectral resolution through the LEH at $21.6^{\circ}$ with an 18 -channel absolutely calibrated soft $\mathrm{x}$-ray power diagnostic, Dante [13]. Dante has a partial view of the initial laser spots on the hohlraum back wall and provides a measure of the radiation flux that includes both the primary laser-plasma emission and the re-emitting walls (see Fig. 1a). The total backscattered laser energy measured with a Full Aperture Backscattering Station (FABS) [14], and a Near Backscattering Imager (NBI) [15] was $<0.6 \%$. A static x-ray imager (SXI) 
confirmed that the beams propagate through the LEH without striking the outside walls of the hohlraum. Finally, the hot electron production inside the hohlraum was inferred from 20-100 keV absolutely calibrated x-ray spectra of the electron bremsstrahlung emission [16]. The measured hot electron fraction (temperature) was $<\sim 1 \%(30 \mathrm{keV})$ in all hohlraums except the smallest, scale-3/4 hohlraum where it was $4 \%(30 \mathrm{keV})$.

A series of experiments using $2 \mathrm{~ns}$ flattop pulses and variable laser energy in the 5-13 kJ range was first performed to measure the radiation temperature scaling with laser power and hohlraum size in a regime similar to previous hohlraums $[8,9,17]$ where minimal plasma filling is expected. Figure 1a shows measured and predicted radiation temperatures for scale-1 $(1.6 \mathrm{~mm}$ diameter, $1.5 \mathrm{~mm}$ long $)$ and scale-3/4 $(1.2 \mathrm{~mm}$ diameter, $1.1 \mathrm{~mm}$ long) hohlraums with a LEH size of 0.75 of the hohlraum diameter. The peak radiation temperature scales as expected with both the laser power and hohlraum size [19] and agrees with LASNEX simulations [18] within the $2 \%$ Dante radiation temperature error bar. Figure $1 \mathrm{~b}$ shows $9 \mathrm{keV}$ side view images at the end of the $2 \mathrm{~ns}$ pulse for a scale- 1 and scale- $3 / 4$ hohlraum driven at the same $6.7 \mathrm{TW}$ laser power. In the scale-1 hohlraums the emission is localized at the back wall, indicating no plasma filling. The smaller scale-3/4 hohlraum also shows bright emission from the back wall and some emission indicating that laser absorption by inverse bremsstrahlung in the LEH region becomes important by the end of the pulse.

Figure $2 \mathrm{~b}$ shows that the Au L-shell emission in the LEH region for a scale-1 hohlraum ( $0.8 \mathrm{~mm}$ LEH) eventually dominates when irradiated by a longer $6 \mathrm{~ns}$ laser pulse. We apply LASNEX simulations to calculate the ablation from the gold hohlraum walls by soft $\mathrm{x}$ rays and the cylindrically inward motion of the ablated plasma (Fig. 2a). First, the low-density ablation plasma moves into the beams path and is directly heated by the laser 
beams. This creates a high plasma pressure on the hohlraum axis retarding complete closure of the hohlraum, which is an important part of the hydrodynamics. Second, rollover of the internal radiation temperature occurs at $\sim 4$ ns when the ablated plasma moving inward from the LEH begins to significantly absorb and refract the beam at the LEH. At this time, $\mathrm{n}_{\mathrm{e}} \sim 0.25 \mathrm{n}_{\mathrm{c}}$ at the center of the LEH and $>0.5 \mathrm{nc}$ at the outside of the beam. By 5.6ns (fig 2) the LEH plasma completely absorbs the laser beams. As a consequence, the hard $\mathrm{x}$-ray radiation production migrates from the hohlraum back wall to the region of the LEH. This behavior is well reproduced by LASNEX post processed calculations of the Au L-shell emission (Fig. 2c) particularly the sudden transition from back wall to LEH dominated emission at $\sim 4 \mathrm{~ns}$. The radial expansion of the LEH plasma emission is lower in calculations than in experiments suggesting that the simulated plasma stagnation on hohlraum axis is stronger than in experiments.

In addition to the scale-1 hohlraum irradiated with a 6 ns laser pulse, we performed long pulse experiments using larger, scale-3/2 hohlraums (2.4 mm diameter, $2.25 \mathrm{~mm}$ long, $1.4 \mathrm{~mm} \mathrm{LEH)} \mathrm{demonstrating} \mathrm{that} \mathrm{our} \mathrm{modeling} \mathrm{correctly} \mathrm{predicts} \mathrm{the} \mathrm{size} \mathrm{scaling} \mathrm{of}$ plasma fill limits and the roll-over of the internal radiation temperature. With the same 6 ns laser pulse into the larger scale-3/2 hohlraum, the Au L-shell emission is considerably stronger at the back wall than at the LEH, indicating that the hohlraum fill plasma density is moderate and that the laser still propagates into the hohlraum until the end of the heating. However, when irradiating the same scale-3/2 hohlraum with a longer, $9 \mathrm{~ns}$ laser pulse of similar energy, we observe strong emission in the LEH at $\mathrm{t}=7 \mathrm{~ns}$.

Figure 3 shows the radiation temperature through the LEH $\mathrm{T}_{\mathrm{LEH}}$ for the long pulse experiments measured by Dante, and simulated by LASNEX. Here $T_{\mathrm{LEH}}$ is defined as the equivalent radiation temperature of the absolute flux measured by Dante. Figure 3 also 
shows the corresponding measured and simulated "M-band flux" (radiation $>2 \mathrm{keV}$ ). Both the 9 ns scale- $3 / 2$ and the 6 ns scale- 1 results (b and c) show two characteristic signatures of roll-over not seen in the $6 \mathrm{~ns}$ scale- $3 / 2$ result (a). Most prominent is the rise in $\mathrm{Au}$ M-band flux. These $>2 \mathrm{keV}$ x-rays are produced by the dense LEH plasma that absorbs the laser beams and that is located where its emission is measured by Dante. In order to infer a roll-over time $\tau$ from our experiments, we use the time of the sudden rise in $\mathrm{Au}$ M-band flux. Less prominent is a sudden rise in $\mathrm{T}_{\mathrm{LEH}}$ that occurs when the $\mathrm{LEH}$ plasma becomes dense enough to entirely stop the laser beams.

Further, Fig. 3 shows the calculated "internal $T_{R}$ ", which is the radiation temperature that would drive an HED package located inside the hohlraum. This calculation shows "rollover" at the time $\tau$ (Fig. $3 b$ and c) when the LEH plasma is dense enough to absorb entirely the laser energy that coincides with the sudden rise in M-band emission and the rise in LEH temperature.

In addition to detailed numerical simulations, these results can be understood and extrapolated to higher laser energies and powers by applying a simple analytic model for radiation temperature limits. This model is based on the increased hydrodynamic losses and thin coronal radiative losses proportional to $n_{e}^{2}\left(n_{e}\right.$-electron density) [17] that occur when the laser absorption region migrates to the LEH as the hohlraum fills with plasma, leading to the roll-over in the internal radiation temperature. In our model these losses become important at the LEH when the inverse bremsstrahlung absorption length $\lambda_{\mathrm{IB}}$ [20] in the laser heated LEH plasma becomes shorter than the LEH radius r:

$$
\lambda_{\mathrm{IB}}=\mathrm{T}_{\mathrm{e}} 1.5 / 200 \mathrm{Z}_{\mathrm{H}} \mathrm{n}_{\mathrm{e}}^{2}=0.7 \mathrm{r}
$$

where $\lambda_{\mathrm{IB}}$ and $\mathrm{r}$ are in units of $\mathrm{cm}$, Coulomb logarithm is set to $7, \mathrm{n}_{\mathrm{e}}$ is the electron density in units of critical density $n_{c}$ for the laser wavelength used, $T_{e}$ is the electron temperature 
in $\mathrm{keV}$, and $\mathrm{Z}_{\mathrm{H}}$ is the average coronal charge state of the plasma fill. Equating the inverse Bremsstrahlung absorption to the electron conduction losses away from the laser heated channel inside the hohlraum sets one constraint on $n_{e}$ and $T_{e}[1]$ :

$$
\mathrm{PL}_{\mathrm{L}}=0.14 \mathrm{~T}_{\mathrm{e}}^{5} / \mathrm{Z}_{\mathrm{H}}{ }^{2} \mathrm{n}_{\mathrm{e}}^{2}
$$

where $\mathrm{P}_{\mathrm{L}}$ is the power of the flattop laser pulse in TW. Pressure balance between the laser heated plasma fill and the cold x-ray ablated Au wall with average ion density $\mathrm{n}_{\mathrm{i}}$ and charge state $\mathrm{Z}$ defines another constraint on $\mathrm{n}_{\mathrm{e}}$ and $\mathrm{T}_{\mathrm{e}}[1]$ :

$$
10 \mathrm{n}_{\mathrm{e}} \mathrm{T}_{\mathrm{e}}=\mathrm{Zn}_{\mathrm{i}} \mathrm{T}_{\mathrm{R}}
$$

where the factor of 10 accounts for the internal radiation temperature $T_{R}$ that is expressed in units of heV, and $\mathrm{n}_{\mathrm{i}}$ is in units of critical density. The average x-ray ablated ion density is proportional to the ablated wall areal mass density divided by the hohlraum radius $\mathrm{R}$. For a Au hohlraum wall [1] this gives us a relation between the ion density $n_{i}$ and $T_{R}$ :

$$
\mathrm{n}_{\mathrm{i}}=.0007 \mathrm{~T}_{\mathrm{R}} 1.86 \mathrm{t}^{0.54 / \mathrm{R}}
$$

where the hohlraum radius $\mathrm{R}$ is in $\mathrm{cm}$ and $\mathrm{t}$ is the time after the start of the laser drive. The average $\mathrm{X}$-ray ablated $\mathrm{Au}$ ionization state $\mathrm{Z}$ as a function of the radiation temperature $T_{R}$ is given by $Z=23 T_{R} 0.45[1]$ and the average laser heated $A u$ ionization state $Z_{H}$ as a function of electron temperature $\mathrm{T}_{\mathrm{e}}$ is given by $\mathrm{Z}_{\mathrm{H}}=45 \mathrm{~T}_{\mathrm{e}} 0.2$ [21].

Another relation between the internal radiation temperature $T_{R}, t$ and $R$ is given by a traditional hohlraum power balance omitting thermal radiation losses out of the LEH which are lower than wall losses for the LEH sizes used here. This power balance assuming constant $x$-ray conversion efficiency (C.E.) of $75 \%$ and $100 \%$ absorbed laser energy is given by [1]:

$$
\mathrm{P}_{\mathrm{L}} \propto \mathrm{T}_{\mathrm{R}}^{4} \mathrm{R}^{2}(1-\alpha)=110 \mathrm{~T}_{\mathrm{R}} 3.3 \mathrm{R}^{2 / \mathrm{t}^{0.4}}
$$


where the radiative wall loss fraction is $(1-\alpha)=0.45 / T_{R} 0.7 t^{0.4}$. This assumes a cylindrical halfraum with length $\mathrm{L}=2 \mathrm{R}$, as in the experiments described here. Combining equations (1)-(5) gives the roll-over radiation temperature $T_{\max }=T_{R}(\tau)$ in terms of laser power, roll-over time $\tau$ and LEH radius $r$ :

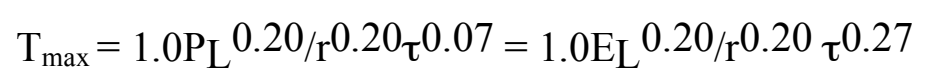

where $T_{\max }$ is in heV units, the flattop laser power (energy) $P_{L}\left(E_{L}\right)$ is in TW (kJ), the filling time $\tau$ is in ns and the LEH radius $r$ is in $\mathrm{cm}$. The middle expression in Eq. (6) is applicable when the laser is power limited and the (right-hand) expression is applicable when the pulse length is long enough that the laser is energy limited. The relations (1)(5) can be used to derive all significant hohlraum plasma parameters and the hohlraum size R. The optimum hohlraum size decreases for shorter fill (roll-over) times $\tau$ as smaller hohlraums will get hotter and fill faster with plasma.

As shown in Fig. 3, the simulated Dante $\left(\mathrm{T}_{\mathrm{LEH}}\right)$ and internal $\left(\mathrm{T}_{\mathrm{R}}\right)$ temperatures have similar values at the roll-over time, which allows us to compare $\mathrm{T}_{\max }$ (Eq. (6)) directly to measured Dante temperature $\left(\mathrm{T}_{\mathrm{LEH}}\right)$. Figure 4 plots the experimental Dante temperatures (full circles) at the fill times $\tau$ and the corresponding $\mathrm{T}_{\max }$ limits calculated with Eq. (6) (crosses) showing good agreement. Also shown is a data point for a smaller scale-3/8 hohlraum, heated by 1 ns laser pulse [22]. We also find that the $\mathrm{T}_{\max }$ limits for the hohlraums with negligible plasma filling are higher than the measured temperatures as expected, validating that for these combinations of laser power, pulse length and LEH size, higher internal temperatures could be reached using smaller hohlraums.

Figure 4 also shows analytical curves that describe the $T_{R}$ limits (Eq. (6)) imposed by plasma filling for both the current NIF first quad experiment and for future experiments 
with the full NIF laser facility used to heat hohlraums with 192 beams through two LEHs. The two curves are calculated using Eq. (6) assuming a constant LEH radius of $0.3 \mathrm{~mm}$, consistent with the minimum NIF laser spot size and a maximum angle of incidence of $50^{\circ}$, and a full NIF hohlraum aspect ratio of $\mathrm{L}=3 \mathrm{R}$. Extrapolating our analytic model predictions to full NIF hohlraum performance limits, suggests a maximum achievable radiation temperature of $\mathrm{T}_{\max }>700 \mathrm{eV}$.

In conclusion, we have demonstrated hohlraum performance limits consistent with simulations and analytic modeling for both low and high plasma filling conditions. The plasma filling inferred by gated imaging of Au L-shell emission and Dante radiation temperature and M-band flux measurements were used to determine the fill time $\tau$. The agreement between measurements and detailed LASNEX calculations constitute compelling evidence that the dynamics of bulk hohlraum filling is well understood and that hohlraums can work above $0.1 \mathrm{n}_{\mathrm{c}}$ filling. Furthermore, these observations agree with our analytical model based on limits imposed by hydrodynamic and coronal radiative losses that allows us to predict the radiation production limits for full NIF in $T_{R}-\tau$ space. These are the first results that corroborate the limits imposed by hohlraum plasma filling in hohlraum radiation performance for indirect drive ICF and HED experiments.

This work would not have been possible without a large team which includes the NIF operations staff, the Bechtel Nevada LO calibrations staff, the target area staff and valuable contributions from G. Armstrong, D.E. Bower, S. Burkhardt, C. Gates, J. Grinold, D. Hargrove, M. Hermann, S. Johnson, J. Kamperschroer, J. Kimbrough, T. Kohut, M. Landon, C. Marshall, J. Menapace, K. Piston, V. Rekow, V. Roberts, A. Warrick, P. Watts, and P.E. Young. The authors would also like to thank M-C Monteil, 
CEA, France, and R.M. Stevenson, AWE, for valuable discussions. This work was performed under the auspices of the U.S. Department of Energy by the University of California, Lawrence Livermore National Laboratory under Contract No. W-7405-ENG48.

\section{References}

[1] J.D. Lindl, Phys. Plasmas 2, 3933 (1995).

[2] J.D. Lindl et al., Phys. Plasmas 11, 339 (2004).

[3] B. Thomas, AWE, private communication, 1995

[4] G.D. Tsakiris and R. Sigel, Phys. Rev. A 38, 5769 (1988).

[5] R.M. Stevenson et al., Phys. Rev. Lett. 94, 055006 (2005).

[6] B. Remington et al., Metallurgical and Mat. Trans. A, 35A, 2587 (2004).

[7] C.A. Back et al., Phys. Rev. Lett. 84, 274 (2000).

[8] S.H. Glenzer et al., Phys. Rev. Lett. 80, 2845 (1998).

[9] E. Dattolo et al., Phys. Plasmas 8, 260 (2001).

[10] G.H. Miller, E.I. Moses and C.R. Wuest, Nucl. Fusion 44 S228 (2004).

[11] S.H. Glenzer et al.,Nucl. Fusion 44, 185 (2004).

[12] L.J. Suter et al., Rev. Sci. Instrum. 68, 838 (1997).

[13] E.L. Dewald et al., Rev. Sci. Instrum. 75, 3759 (2004).

[14] D. Froula et al., Rev. Sci. Instrum. 75, 4168 (2004).

[15] A.J. Mackinnon et al., Rev. Sci. Instrum. 75, 4183 (2004).

[16] J.W. McDonald et al., Rev. Sci. Instrum. 75, 3753 (2004).

[17] L.J. Suter et al., Phys. Plasmas 3, 2057 (1996).

[18] G.B. Zimmerman, W.L. Kruer, Comm. Plasma Phys. Contr. Fusion 2, 51 (1975). 
[19] R. Sigel et al., Phys. Rev. Lett. 65, 587 (1990).

[20] T.W. Johnston and J.M. Dawson, Phys. Fluids 16, 722 (1973).

[21] R.W. Lee et. al., JQSRT 58, 737 (1997).

[22] D. Hinkel et al., Phys. Plasmas, 12, 056305 (2005). 


\section{Figure captions}

Figure 1 Dante view and Dante measurements of hohlraum targets with initial laser spots on the wall shown as dark circle. (a) Radiation temperature measured with Dante (continuous lines) and calculated (dashed lines) for 2 ns flattop laser pulses and variable hohlraum scale and laser power; (b) Gated x-ray ( $>9 \mathrm{keV}$ ) side view images at $1.9 \mathrm{~ns}$ for 6.7 TW drive in scale-1 and 3/4 hohlraums.

Figure 2 (a) Cross-section of electron density profiles and laser ray propagation calculated with 2D Lasnex code in Scale-1 hohlraum heated by $2.7 \mathrm{TW}, 6$ ns laser pulse (b) Measured and (c) Calculated hard x-ray $(>9 \mathrm{keV})$ gated images.

Figure 3 Radiation temperature history as measured by Dante through LEH (continuous thick line) and as simulated by LASNEX (full squares). Circles are predicted internal radiation temperature. Measured (continuous thin line) and calculated (triangles) M-band (>2 keV) flux are plotted on RHS scale. (a) scale-3/2 hohlraum driven by 2.7 TW in 6 ns, (b) scale-3/2 driven by $1.9 \mathrm{TW}$ in $9 \mathrm{~ns}$ and (c) scale- 1 driven by $2.7 \mathrm{TW}$ in 6 ns flattop laser pulse.

Figure 4 Dante measured temperatures $\mathrm{T}_{\mathrm{LEH}}$ at the roll-over time $\tau$ and the corresponding analytical limits (crosses) calculated with Eq. (6) using experimental values of LEH radius $\mathrm{r}$ and laser power. Continuous and dashed black lines are Eq. (6) analytic model limits for a constant LEH radius $\mathrm{r}=0.3 \mathrm{~mm}$ for $9 \mathrm{TW}, 16 \mathrm{~kJ} 1$ quad NIF halfraums and for $600 \mathrm{TW}, 1.8 \mathrm{MJ}$ NIF hohlraum. 
Figure 1

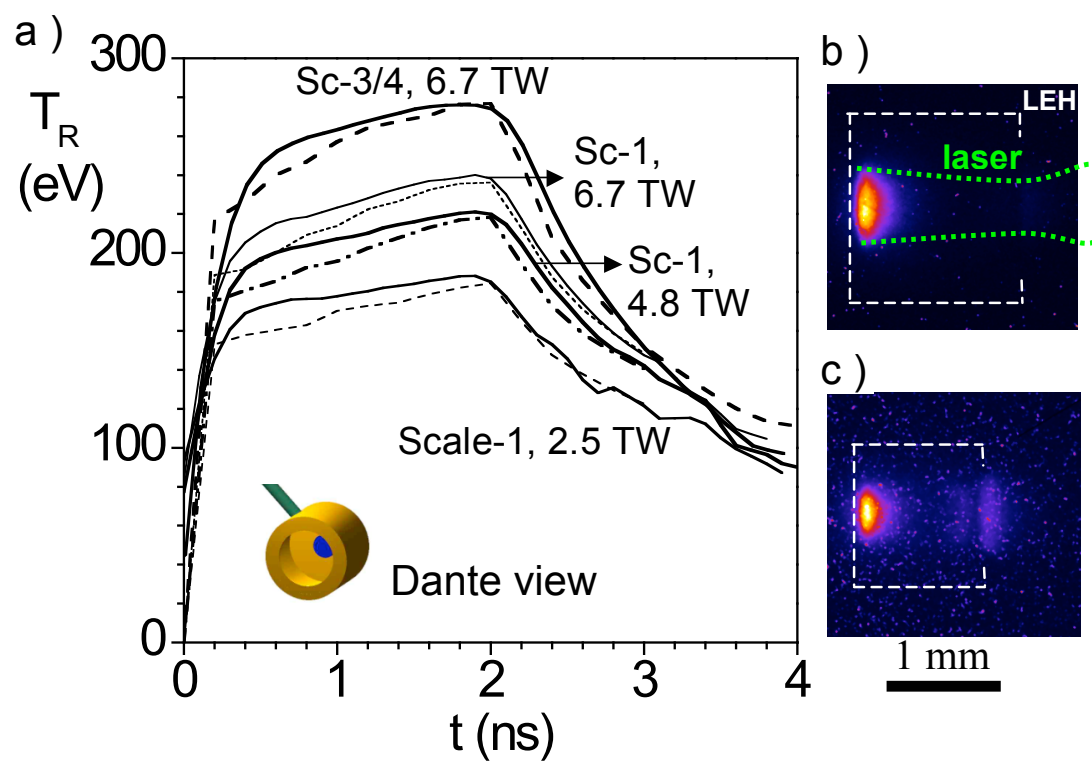




\section{Figure 2}

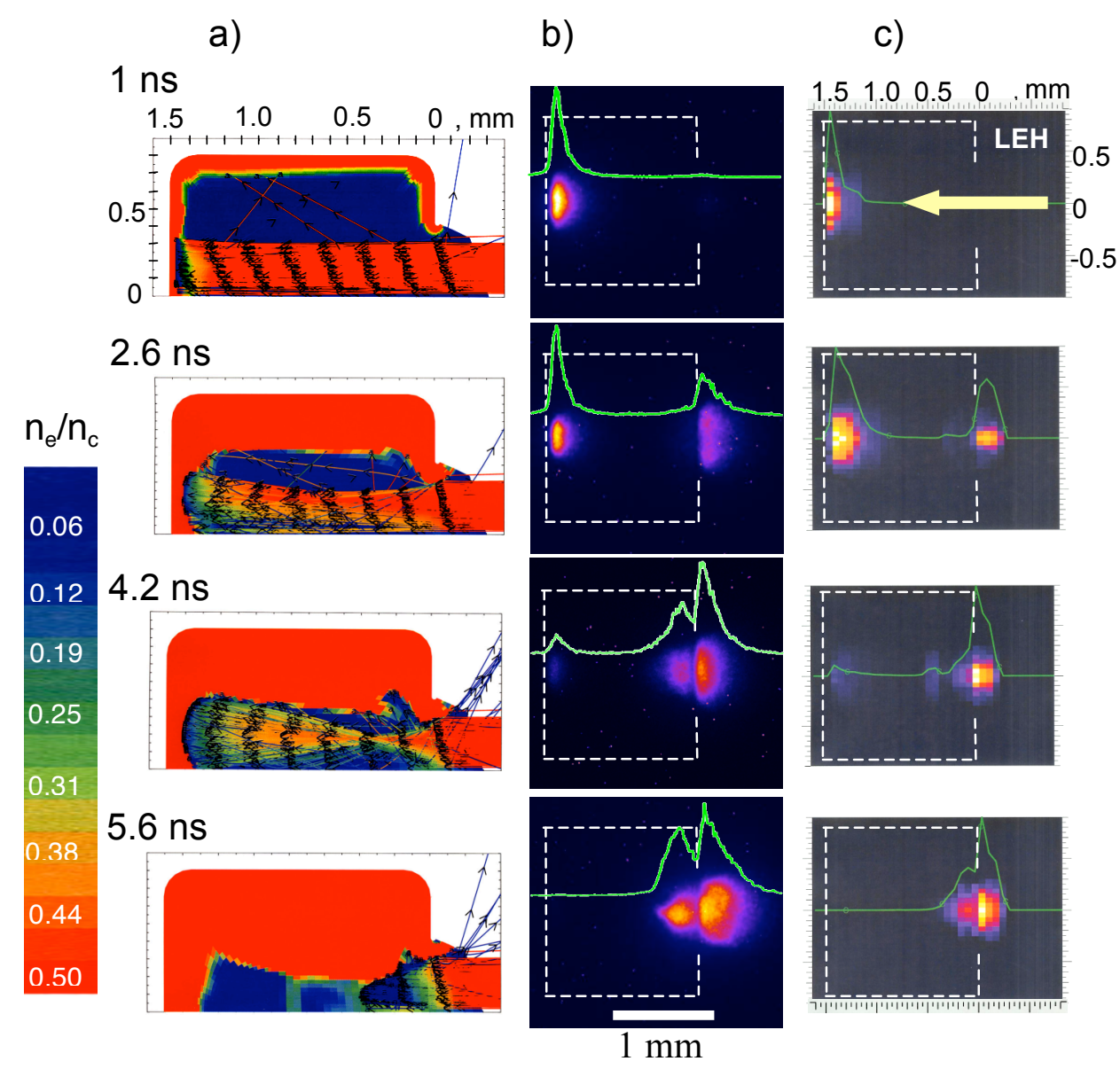


Figure 3
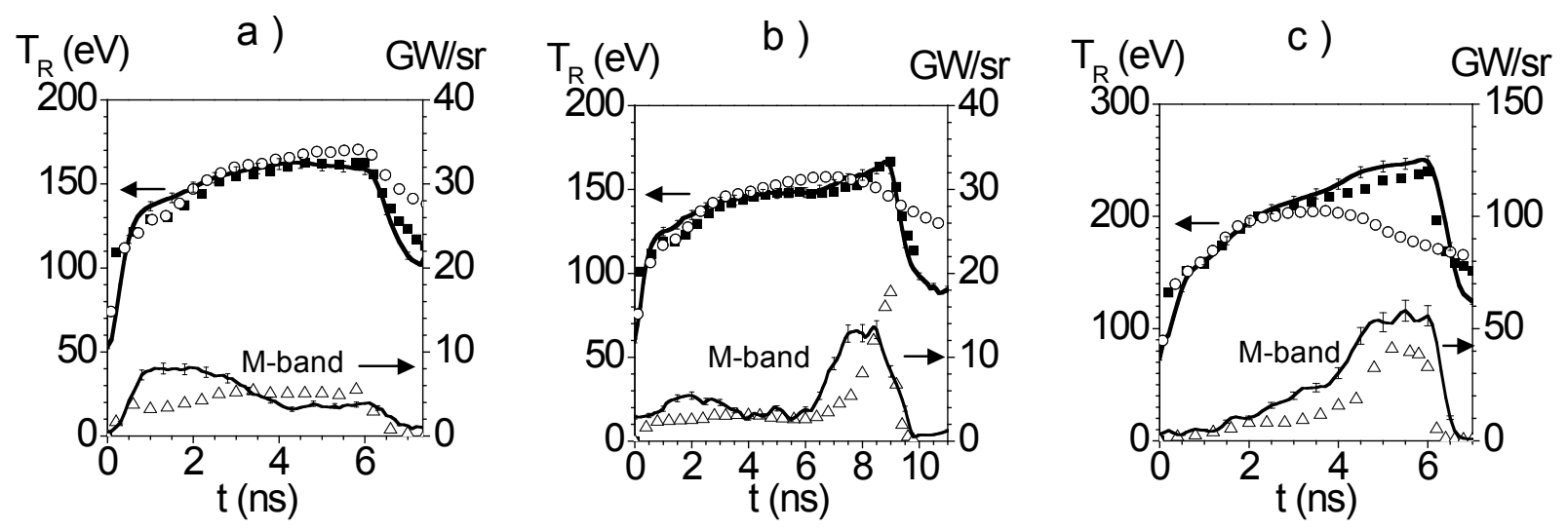
Figure 4

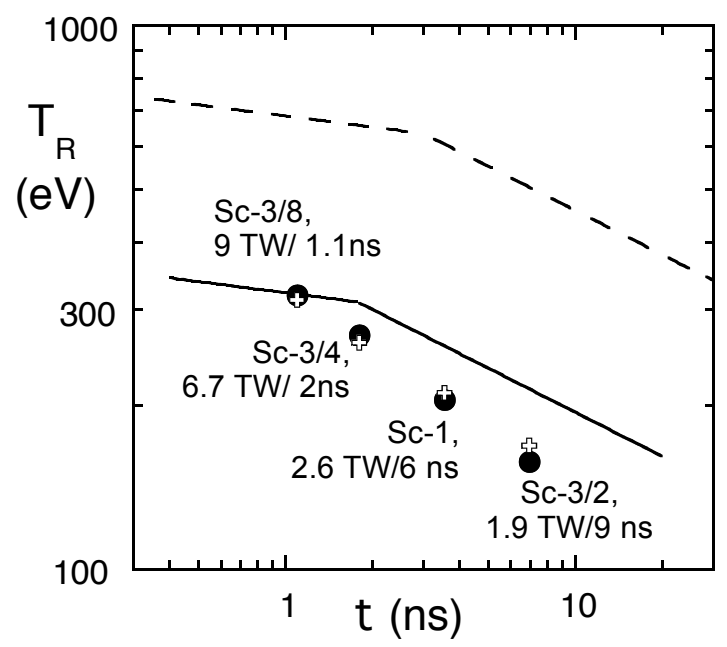

